Disponível em

http://www.anpad.org.br/rac

RAC, Rio de Janeiro, v. 19, n. 5, art. 4, pp. 606-625, Set./Out. 2015

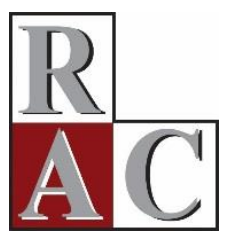

\title{
Análise dos Efeitos em Mercado de Capitais Decorrentes de Fusões: O Caso BRF S.A.
}

Analysis of Effects in Capital Markets Resulting from Mergers: The BRF Case

Patrícia Ribeiro Romano Universidade Federal do Rio Grande do Norte - UFRN

Vinicio de Souza e Almeida Universidade Federal do Rio Grande do Norte - UFRN 


\title{
Resumo
}

Este trabalho investigou os possíveis efeitos no mercado de capitais ocorridos antes, durante e após a fusão da Sadia e Perdigão (nova BRF S.A), anunciada em 19 de maio de 2009. Para isso, relata, analisa e apresenta, através de estudo de eventos, o comportamento dos retornos extraordinários em oito eventos, selecionados em diferentes subperíodos, tanto para as duas empresas integrantes da fusão como para seus principais concorrentes de mercado. Os eventos foram divididos em: seis relacionados à fusão e aquisição (F\&A) e dois não relacionados. Os resultados mais significativos estatística e economicamente foram os primeiros. Houve retornos extraordinários positivos e estatisticamente significativos tanto para empresa Sadia (adquirida) quanto para a adquirente (Perdigão), sendo que os retornos da firma adquirida foram maiores do que os retornos da empresa adquirente. Outra verificação que este estudo revelou foi que a fusão resultou em preços acionários maiores para as empresas rivais em todos os períodos analisados, apresentando retornos extraordinários positivos e significantes. Além disso, este trabalho está em linha com a hipótese de probabilidade de aquisição.

Palavras-chave: estudo de eventos; fusões e aquisições; retornos extraordinários.

\begin{abstract}
This study investigated the possible effects on the capital markets that occurred before, during and after the merger between Sadia and Perdigão (new BRF) announced on May 19, 2009. Through event study analysis this research reports, analyzes and presents the behavior of abnormal returns in eight selected events in different periods, both for the two companies included in the merger process as well as for their main competitors in the market. The events were divided into six related to the merger and acquisition and two unrelated to the M\&A. The most statistically and economically significant results came from the events related to the merger. There were positive and statistically significant abnormal returns for both the acquiring company and the acquired company. Returns for the acquired firm were higher than the returns of the acquiring company. Another result that this study showed was that the merger resulted in higher stock prices for rival firms in all periods analyzed, showing positive and significant abnormal returns. This result is in line with the acquisition probability hypothesis.
\end{abstract}

Key words: event studies; merger and acquisitions; abnormal returns. 


\section{Introdução}

As operações de fusões e aquisições (F\&As) vêm crescendo no Brasil, desde o início dos anos 2000. Elas foram incentivadas pela boa fase da economia brasileira, junto com o aumento da internacionalização das empresas e da incerteza no ambiente de negócios. Em 2007, ocorreram 317 negócios fechados, segundo dados da Bloomberg ${ }^{\circledR}$. Em 2008, subiu para 470. No ano seguinte, caiu para 312, mas obteve um aumento, em 2010, para 490 operações. Em 2011, foram efetuadas 667 transações, o que significa um crescimento de $36,12 \%$ em relação a 2010.

Apesar desse crescimento do número de operações, Leal, Almeida e Bortolon (2013) encontraram poucos estudos no país que abordam esse assunto. Segundo os autores, só foram publicados oito artigos nacionais com o tema no período de 2000 a 2010, nos seguintes periódicos selecionados para análise: Brazilian Administration Review; Economia Aplicada; Gestão \& Produção; Revista Brasileira de Economia; Revista Brasileira de Finanças; Revista Contabilidade \& Finanças; Revista de Administração Contemporânea; Revista de Administração Mackenzie; Revista de Administração da Universidade de São Paulo; Revista de Administração de Empresas; Revista de Produção. Para Steinberg e Silva (2009), as razões para esse baixo número de estudos podem ser a falta de divulgação da base de dados das operações e a dificuldade de obtê-los, aliadas ao fato de que o aumento de transações é um acontecimento que se intensificou apenas ultimamente.

As fusões e aquisições têm resultado em muitas discussões a respeito da real eficiência em se criar valor para o acionista. A maior parte da literatura econômico-financeira sobre F\&As analisa o impacto dessas operações no valor de mercado das firmas participantes (adquirente e adquirida). Estudos como os de Datta, Pinches e Narayanan (1992), Mackinlay (1997) e Moeller, Schilingemann e Stulz (2004) mostraram retorno extraordinário positivo e significativo para as empresas-alvo (adquiridas) e próximo a zero para as empresas compradoras (adquirentes).

Os supostos ganhos de sinergia e eficiência, principais anseios apontados como propulsores dessas operações, precisam ser mensurados. Os ganhos podem não ocorrer em casos de reorganizações corporativas malfeitas, gerando maiores custos para as empresas. Além disso, os ganhos também podem ocorrer com as empresas concorrentes das empresas-alvo da fusão. Eckbo (1983), Hosken e Simpson (1998) e Fee e Thomas (2004) analisaram o potencial anticompetitivo das fusões utilizando informações do mercado de capitais e evidenciaram os ganhos que concorrentes podem ter com essas.

Hosken e Simpson (1998), ao analisar quatro fusões nos Estados Unidos na década de 1980, apontaram quatro ganhos que os rivais podem ter com processos de fusão: (a) a empresa que é concorrente se beneficia com maiores lucros, dados os preços mais altos advindos de uma fusão; (b) a empresa que é concorrente se beneficia quando uma fusão revela oportunidades de obter eficiências via fusão, que antes não conheciam; (c) a empresa concorrente se beneficia quando as empresas que participam do processo de fusão são forçadas a vender ativos com um desconto para satisfazer decisões antitrustes; (d) a empresa concorrente pode se beneficiar se as empresas, no processo de fusão, aumentarem o esforço de marketing, o que pode aumentar a visibilidade do setor como um todo e criar demanda de mercado.

Dessa forma, as fusões e aquisições são processos com potencial para reconfigurar a dinâmica das relações empresariais. No Brasil, o volume financeiro envolvido nos processos de F\&As é considerável. Segundo dados em Associação Brasileira das Entidades dos Mercados Financeiro e de Capitais (Anbima, 2013), as fusões e aquisições movimentaram $\mathrm{R} \$ 43$ bilhões no primeiro semestre de 2013. Em todo o ano de 2012, o volume dos anúncios chegou a $\mathrm{R} \$ 122,3$ bilhões.

Com essa expressão financeira e o recente interesse de acadêmicos e profissionais de mercado no Brasil, vislumbra-se espaço para trabalhos voltados à observação de possíveis mudanças no comportamento dos retornos, tanto das empresas participantes quanto de suas concorrentes, quando da ocorrência e efetivação desses eventos. Neste trabalho, analisamos a fusão entre Sadia e Perdigão, mostrando os efeitos decorrentes tanto para as duas empresas integrantes da fusão como para seus 
principais concorrentes de mercado. Empregamos a metodologia de estudo de eventos com o objetivo de investigar os possíveis efeitos no mercado de capitais antes, durante e após a fusão Sadia-Perdigão. Os resultados da análise dos eventos relacionados com essa fusão adicionam à literatura sobre a eficiência da operação de fusão ao constatar que as fusões ajudam as empresas e a indústria a crescerem e reestruturarem-se, particularmente em resposta às possíveis crises enfrentadas.

Além de confirmar algumas suposições teóricas (e.g. Agarwal \& Singh, 2006; Fee \& Thomas, 2004; Song \& Walking, 2000) e refutar outras (e.g. Bernile \& Lyandres, 2013; Eckbo, 1983), este trabalho pode ser útil a agentes de mercado na área de investment banking, ao descrever o potencial comportamento dos preços em operações de $\mathrm{F} \& \mathrm{~A}$. A regularidade dos retornos também mostra que talvez sejam necessárias iniciativas regulatórias que incentivem maiores transparência e fluxo de informações, assim, diminuindo a ocorrência de retornos extraordinários.

\section{Referencial Teórico}

Nos Estados Unidos e em países europeus, existem pesquisas sobre fusões e aquisições que abordam a teoria antitruste. Essa teoria consiste em políticas de defesa da concorrência que tendem a avaliar não somente os efeitos anticompetitivos, mas também os potenciais impactos em termos de ganhos de eficiência econômica (Ponde, Fagundes, \& Possas, 1997).

Em teoria, os efeitos anticompetitivos das F\&As são negativos, pois o anúncio e a efetivação das fusões e aquisições entre concorrentes podem resultar em acumulação de poder de mercado somente para as empresas participantes (adquirente e adquirida). Porém as evidências empíricas apresentadas por Eckbo (1983), ao analisar fusões horizontais nos Estados Unidos, no período de 1963 a 1978, indicaram que as operações que passaram pela triagem do governo não foram, em geral, anticompetitivas.

Song e Walkling (2000), Fee e Thomas (2004), Shahrur (2005) e Bernile e Lyandres (2013), também, analisaram os retornos extraordinários das firmas rivais e encontraram que as empresas concorrentes obtiveram retornos extraordinários positivos logo após os anúncios de F\&As. Uma das possíveis explicações para esses retornos positivos das empresas concorrentes seria a hipótese de colusão, a qual vem de uma interpretação mais estrita dentro das consequências advindas do poder de mercado. Essa hipótese prevê um comportamento combinado entre empresas de um mesmo setor, com o objetivo de elevar os preços em mercado acionário e repartir mercados. Ademais, suas implicações são expressas em termos do desempenho extraordinário em resposta a dois anúncios públicos: o primeiro corresponde ao anúncio da proposta de F\&A; e o segundo, ao anúncio do julgamento da aprovação do processo pelo órgão responsável pela defesa da concorrência.

Para confirmar essa hipótese, é necessário haver retornos positivos para as empresas participantes e rivais no momento do anúncio do processo de fusão ou aquisição. Além disso, deve haver retornos negativos para as firmas participantes e concorrentes após o anúncio da legalização do processo de F\&A pelo órgão antitruste responsável.

Eckbo (1983) e Bernile e Lyandres (2013), em seus trabalhos, rejeitaram a hipótese de colusão, que poderia explicar os retornos positivos para as empresas rivais no momento do anúncio da operação de F\&A. Os resultados de Song e Walkling (2000) também rejeitaram a hipótese de colusão. Ademais, os autores elaboraram a hipótese de probabilidade de aquisição para explicar as razões desses retornos positivos. Tal hipótese prevê que as empresas rivais obtêm retornos positivos porque podem ser as futuras empresas a serem adquiridas.

Além de afetar os resultados das firmas rivais, as fusões e aquisições impactam também nos retornos das empresas participantes dos processos de F\&As. Dessa maneira, parte da literatura econômico-financeira sobre fusões e aquisições analisou o impacto dessas operações no valor de mercado das empresas participantes (alvo e adquirente). As pesquisas empíricas, comumente, avaliam os benefícios econômicos proporcionados pelas fusões ou aquisições com base na resposta dada pelo 
mercado acionário. As mudanças nos preços das ações das empresas adquirentes e alvo representam a crença dos participantes de mercado no valor criado pela fusão ou aquisição.

Um dos primeiros artigos da literatura sobre o mercado de controle corporativo com relação a fusões e aquisições é de Manne (1965). Nele, o autor discute os vários argumentos a favor e contra essas operações. Argumenta que as fusões representam um resultado natural em um mercado eficiente de controle corporativo e, consequentemente, fornece proteção para os acionistas.

Datta et al. (1992), Moeller et al. (2004) e Hackbart e Morellec (2008) indicaram que as fusões e aquisições corporativas geram ganhos, que beneficiam os acionistas da empresa-alvo, e que a organização adquirente não apresentou perdas. Em seus estudos, concluíram que há retorno extraordinário para as empresas-alvo e próximo a zero para as firmas adquirentes. Os mesmos resultados foram encontrados por Mackinlay (1997), que desenvolveu um trabalho analisando os principais estudos em fusões e aquisições das décadas de 1960 a 1980 e revelou um enorme corpo de evidências empíricas sobre F\&As com uso de estudo de eventos.

Agarwal e Singh (2006) encontraram resultados diferentes ao analisar processos de fusões e aquisições. Os autores mostraram que tanto os acionistas adquirentes quanto os alvos obtêm retornos anormais em F\&As. Andrade, Mitchell e Stafford (2001) e Kuipers, Miller e Patel (2009), no entanto, obtiveram outros resultados. Os autores constataram que as F\&As foram benéficas apenas para os acionistas das firmas adquiridas, com pequenas perdas para acionistas das firmas adquirentes.

Diversos estudos tentaram encontrar justificativas para essas diferenças nos retornos das empresas participantes das fusões e aquisições. Moeller et al. (2004), Gorton, Kahl e Rosen (2009) e Phalippou, Xu e Zhao (2013) detectaram que o tamanho das empresas participantes influencia as diferenças entre seus retornos. Moeller et al. (2004) expõem, em sua pesquisa, que as pequenas empresas se saem melhor do que as grandes quando fazem um anúncio de aquisição. Bhagat, Dong, Hirshleifer e Noah (2005) encontraram que o sucesso das F\&As depende de fatores como o tamanho da adquirida, o nível de oposição da administração da empresa adquirida e da entrada de um segundo adquirente.

No Brasil, os estudos investigaram: o impacto das fusões na riqueza dos acionistas (Brito, Batistella, \& Famá, 2005); os preços ao consumidor na indústria de alimentos e bebidas (Viegas, 2006); o comportamento das ações das empresas envolvidas (Habibe, 2006); e as motivações para as fusões e aquisições (Málaga, 2007).

Camargos e Barbosa (2006) realizaram um estudo de eventos dos anúncios de F\&As de firmas negociadas no mercado de capitais brasileiro e concluíram que os processos analisados não resultaram na criação de valor para os acionistas, e que o mercado se comporta de maneira eficiente no que se refere à forma semiforte. Camargos e Coutinho (2008) analisaram as interfaces da teoria da firma e a fundamentação teórica para as fusões e aquisições; Li e Lucinda (2009) investigaram os possíveis efeitos anticompetitivos da fusão Oi-BrT; Steinberg e Silva (2009) analisaram o impacto da governança corporativa em F\&As; e Pinheiro e Carvalhal (2011) analisaram os retornos anormais das fusões e aquisições.

\section{Motivos para fusões e aquisições}

A aquisição de uma empresa por outra é um investimento efetuado em condições de incerteza. Aplica-se o princípio básico de avaliação: uma empresa deve ser adquirida se gera valor presente líquido positivo para a empresa compradora. $\mathrm{O}$ valor criado por fusões e aquisições pode ser resultado de uma administração mais eficiente, economias de escala, melhorias nas técnicas de produção, combinação de recursos complementares, exploração de ativos mais lucrativos e adequados, exploração do poder de mercado, ou inúmeros outros mecanismos que possam gerar sinergias corporativas (Bradley, Desai, \& Kim, 1988).

Bena e Li (2014) afirmaram que um dos motivos para as F\&As é a obtenção de ativos estratégicos. Os autores constataram que as sinergias obtidas a partir da combinação de capacidades de inovação 
estratégica são importantes direcionadores da aquisição. Em seu estudo, eles mostraram que as empresas com grande portfólio de patentes e baixos gastos com P\&D são adquirentes, enquanto as firmas com alta despesa em $\mathrm{P} \& \mathrm{D}$ e crescimento lento da produção de patentes são empresas-alvo.

Outro motivo defendido, por Almeida, Campello e Hackbarth (2011), para as F\&As é que as empresas em dificuldades financeiras podem ser adquiridas por outras firmas da mesma indústria, mesmo quando não há sinergias operacionais. Os autores chamaram esse tipo de transação de fusão de liquidez. O principal objetivo desse acordo seria realocar a liquidez das empresas que possuem maior estabilidade financeira para as que poderiam ser liquidadas de forma ineficiente devido a uma deficiência de liquidez.

\section{Metodologia de Pesquisa}

Esta pesquisa trabalhou com a mesma metodologia utilizada em diversos estudos sobre fusões e aquisições - o estudo de evento (Mackinlay, 1997). A parte técnica do fato de que um determinado evento pode afetar o valor da empresa e de que essa mudança no valor é refletida através de um retorno extraordinário das ações da companhia. Segundo Mackinlay (1997), a metodologia do estudo de eventos é bastante antiga e vem, ao longo do tempo, sendo sofisticada. Dentre as modificações, destaca-se a verificação do impacto marginal de um tipo de evento na oscilação dos preços dos títulos para períodos em que há mais de um evento no mercado. De acordo com Campbell, Lo e Mackinlay (1997), existem sete etapas para elaboração de um estudo de eventos: (a) definição do evento; (b) seleção do critério; (c) cálculo de retorno normal e de retorno anormal; (d) procedimentos de estimação; (e) procedimentos de teste; (f) resultados empíricos; e (g) interpretação e conclusão.

\section{Definição do evento}

A primeira tarefa dessa metodologia é a definição do evento de interesse. $\mathrm{O}$ dia da ocorrência do evento é definido como data zero, e o período no qual os preços das ações das empresas envolvidas serão examinados, de janela de evento (Mackinlay, 1997).

Mackinlay (1997) afirma que, na prática, o período de interesse é subjetivo e muitas vezes expandido para vários dias, incluindo pelo menos o dia do anúncio e um período após o anúncio. Captase, assim, o efeito no preço potencialmente causado pelo anúncio do evento. A janela de estimação adotada neste trabalho incluiu dados de 15 dias antes e 15 dias depois da data do evento ( $-15 \mathrm{a}+15$ dias), dados de 11 dias $(-5$ a +5 dias $)$ e dados de 7 dias $(-3$ a +3 dias $)$. A escolha das janelas deve-se ao fato do artigo trabalhar com vários eventos muito próximos, consequentemente o período não poderia ser muito grande.

Oito eventos foram definidos e identificados na janela de estimação para que fossem analisados os retornos extraordinários das firmas participantes e concorrentes (ver Tabela 1). Os eventos foram selecionados devido à repercussão entre os agentes de mercado, o que gerou suposições sobre a possível variação dos preços das empresas envolvidas. Dessa forma, o presente trabalho apresenta oito eventos ordenados cronologicamente, divididos em eventos relacionados a $\mathrm{F} \& \mathrm{As}$ e eventos não relacionados diretamente a F\&As. 
Tabela 1

\section{Descrições dos Oito Eventos Analisados}

\begin{tabular}{|c|c|c|c|}
\hline Ordem & Descrição & Data & Relação \\
\hline $1^{\circ}$ evento & $\begin{array}{l}\text { Oferta hostil da Sadia para a compra da } \\
\text { Perdigão. }\end{array}$ & 17 de julho de 2006 & Evento relacionado a F\&A \\
\hline $2^{\circ}$ evento & $\begin{array}{l}\text { Revogação definitiva da Sadia para a } \\
\text { compra da Perdigão. }\end{array}$ & 21 de julho de 2006 & Evento relacionado a F\&A \\
\hline $3^{\circ}$ evento & Situação financeira delicada da Sadia. & 25 de setembro de 2008 & $\begin{array}{l}\text { Evento não relacionado a } \\
\text { F\&A }\end{array}$ \\
\hline $4^{\circ}$ evento & $\begin{array}{l}\text { Anúncio de que a Sadia estava, de fato, } \\
\text { buscando oportunidades para a fusão com } \\
\text { a Perdigão (acordo operacional Sadia- } \\
\text { Perdigão). }\end{array}$ & 12 de março de 2009 & Evento relacionado a F\&A \\
\hline $5^{\circ}$ evento & Anúncio da fusão entre Sadia e Perdigão. & 19 de maio de 2009 & Evento relacionado a F\&A \\
\hline $6^{\circ}$ evento & $\begin{array}{l}\text { Julgamento do processo envolvendo } \\
\text { conselheiros e diretores da Sadia (justiça } \\
\text { condena pela primeira vez por informação } \\
\text { privilegiada). }\end{array}$ & 17 de fevereiro de 2011 & $\begin{array}{l}\text { Evento não relacionado a } \\
\text { F\&A }\end{array}$ \\
\hline $7^{\circ}$ evento & $\begin{array}{l}\text { Primeiro julgamento do CADE sobre a } \\
\text { fusão Sadia e Perdigão (relator do CADE } \\
\text { vota contra a fusão das empresas). }\end{array}$ & 8 de junho de 2011 & Evento relacionado a F\&A \\
\hline $8^{\circ}$ evento & $\begin{array}{l}\text { BRF e CADE selam acordo e fusão entre } \\
\text { Sadia e Perdigão é aprovada. }\end{array}$ & 13 de julho de 2011 & Evento relacionado a F\&A \\
\hline
\end{tabular}

Nota. Fonte: elaborado pelos autores.

\section{Eventos analisados}

$\mathbf{1}^{\circ}$ evento - Oferta hostil da Sadia para a compra da Perdigão.

$2^{\mathbf{o}}$ evento - Revogação definitiva da Sadia para a compra da Perdigão.

Em 2006, a Perdigão promoveu a primeira reestruturação societária para transformar ações preferenciais em ordinárias, com o prêmio de controle reduzido - fez a troca na base de 1 para 1 . Com a operação, a Perdigão juntou-se a uma categoria nova de companhias detentoras do chamado controle difuso, o qual consiste em uma espécie de comando meio a meio, nem tão definido como quando se tem um bloco de controle com 50\% mais 1 das ações com voto, nem tão pulverizado como quando todos os acionistas possuem frações bastante reduzidas do capital. No caso da Perdigão, os maiores acionistas, todos fundos de pensão, detinham aproximadamente $45 \%$ das ações, o que lhes reserva o "quase controle" (Madureira, 2006, p. 42).

Após a consolidação da nova composição acionária da Perdigão, a Sadia iniciou uma tentativa de aquisição submetendo edital de OPA (Oferta Pública de Aquisição) à CVM. Porém a oferta foi rapidamente rejeitada pelo grupo dos fundos de pensão que, contando com outros acionistas não controladores, somavam 55,38\% das ações da Perdigão (Callas, 2009).

$3^{\circ}$ evento - Situação financeira delicada da Sadia.

A Sadia obteve perdas em 2008, pois sua área financeira realizou operações em mercado que resultaram em um prejuízo aproximado de $\mathrm{R} \$ 2,5$ bilhões. O prejuízo foi causado por operações de hedge que apostavam na valorização do real em comparação ao dólar (Exame, 2010). 
A perda causada pela área financeira da empresa levou o valor de mercado da companhia a cair. Além disso, os termos de governança corporativa da Sadia S.A. tornaram-se referência negativa. A fragilidade financeira gerada pelas perdas com os derivativos cambiais foi fundamental para que, em 19 de maio de 2009, fosse anunciada a fusão entre a Perdigão e a Sadia (Barreto, 2011).

$4^{0}$ evento - Anúncio de que a Sadia estava, de fato, buscando oportunidades para a fusão com a Perdigão (acordo operacional Sadia-Perdigão).

A Sadia enfrentou tempos difíceis devido às perdas que sofreu com operações de derivativos cambiais, somando-se, ainda, o risco de governança corporativa e a grande exposição ao mercado externo. Com a situação econômico-financeira extremamente fragilizada, a Sadia divulgou nota admitindo negociações com "terceiros" (Sadia, 2009). Citou ainda "entendimentos recentes" com a Perdigão para "algum tipo de associação" (Sadia, 2009), mas ainda sem acordo. Tanto a Sadia quanto a Perdigão buscavam reduzir custos e fortalecer o caixa para obter capital de giro. As duas companhias tinham como meta não uma fusão, mas apenas um acordo operacional. Entretanto o acordo acabou não vingando (Zafalon, 2009).

\section{$5^{\circ}$ evento - Anúncio da fusão entre Sadia e Perdigão.}

Após a não realização do acordo operacional das duas empresas, a Sadia e a Perdigão receberam incentivos para formarem, juntas, uma gigante mundial do setor alimentício. No processo de fusão previsto, a engenharia financeira e jurídica para incorporação da Sadia pela Perdigão foi de certa forma atípica.

A operação foi realizada em duas fases: na primeira, foi criada a HFF, pertencente à Sadia e futuramente incorporada à Perdigão, cujo nome mudou para BRF. Na segunda etapa, a BRF incorporou os minoritários da Sadia e os detentores de ações preferenciais das duas empresas participantes da fusão, que receberam em troca ações ordinárias para viabilizar a listagem no Novo Mercado da BM\&FBovespa (Ato de concentração $\mathrm{n}^{\circ}$ 08012.004423/2009-18, 2011). Após a fusão, ocorreu uma reorganização societária em que os sócios originais da Perdigão detiveram, na nova companhia, $68 \%$ da BRF, e os da Sadia ficaram com $32 \%$ do novo grupo (Novo, 2009).

$6^{\mathbf{0}}$ evento - Julgamento do processo envolvendo conselheiros e diretores da Sadia (justiça condena, pela primeira vez, por informação privilegiada).

Em 2006, a Sadia realizou uma oferta hostil com apoio do banco ABN Amro Real para adquirir o controle da Perdigão. Dois meses depois do fim da tentativa da incorporação da Perdigão pela Sadia, foi instaurada uma investigação contra um executivo, um conselheiro da Sadia e um superintendente de empréstimos do banco ABN Amro Real, por crime de uso de informações privilegiadas. O caso inaugurou o uso do dispositivo da lei que prevê a punição por crime de insider trading, criado em 2001, com a reforma da Lei das S.A. Os réus da ação penal foram acusados de terem se beneficiado ao utilizar informações sigilosas a que tinham acesso comprando e vendendo recibos de ações (ADRs) das empresas nos Estados Unidos (Parecer do Comitê de Termo de Compromisso, 2008).

$7^{\mathbf{0}}$ evento - Primeiro julgamento do CADE sobre a fusão Sadia e Perdigão (relator do CADE vota contra a fusão das empresas).

O relator do processo de fusão entre a Sadia e a Perdigão, no Conselho Administrativo de Defesa Econômica (CADE), votou contra a conclusão do negócio. Em seu relatório, enumerou diversos desequilíbrios que a fusão causaria no mercado. Ele afirmou que a transação não era a única saída para a sobrevivência da Sadia após os problemas financeiros decorridos de operações com derivativos cambiais em 2008. Ademais, o relator apontou risco de aumento de preço dos produtos vendidos pelas empresas (Ato de concentração $\mathrm{n}^{\circ}$ 08012.004423/2009-18, 2011).

$\mathbf{8}^{\mathbf{o}}$ evento - BRF e CADE selam acordo e fusão entre Sadia e Perdigão é aprovada. 
O Conselho Administrativo de Defesa Econômica (CADE) aprovou a fusão entre Sadia e Perdigão, que deu origem à BRF S.A. O acordo selado previu a suspensão da venda de produtos da marca Perdigão e Batavo. A BRF também ficaria obrigada a alienar cadeias completas de produção (Amato, 2011).

\section{Critério de seleção}

Os comportamentos em mercado de capitais das empresas objeto deste estudo foram analisados a partir de séries de preços de SDIA4 e BRFS3. O procedimento para seleção das empresas rivais foi baseado nos dados da plataforma Bloomberg ${ }^{\circledR}$, em que foram selecionadas as empresas concorrentes através da função Peer Analysis. Em seguida, foram aplicados três filtros para seleção. O primeiro observou se a empresa possui pelo menos um ativo listado na BM\&FBovespa. O segundo analisou critérios de free float. O último critério levou em consideração as negociações mínimas suficientes para que os preços fossem um indicador das expectativas dos mercados e da situação da empresa.

A amostra final incluiu quatro ativos que satisfizeram todos os critérios de seleção da pesquisa. Foram eles: as ações preferenciais da Sadia, com o código SDIA4; as ações ordinárias da Perdigão, com o código BRFS3; as ações ordinárias da Minerva, com o código BEEF3; e as ações ordinárias da Marfrig, com o código MRFG3.

\section{Cálculo de retorno normal e anormal}

Os retornos das ações e do Índice Bovespa (Ibovespa) foram obtidos através do banco de dados Economática $^{\circledR}$. Para cada evento, foram calculados o retorno simples e o acumulado das empresas participantes e concorrentes. O cálculo dos retornos das ações foi baseado nos estudos de Camargos e Barbosa (2006) ao utilizar cotações de fechamento diárias, em reais, ajustadas por proventos, inclusive dividendos, com o intuito de evitar que tais fatos influenciassem os resultados.

Ao levar em consideração a possibilidade de efeitos em mercado devido a choques de informação em tempo contínuo, foi utilizada a forma logarítmica para os retornos $\left(\mathrm{R}_{\mathrm{i}, \mathrm{t}}\right)$, definida por:

$$
\mathrm{R}_{\mathrm{i}, \mathrm{t}}=\ln \left(\frac{P_{i, t}}{P_{i, t-1}}\right)
$$

Sendo $P_{i, t}$ e $P_{i, t-1}$, os preços da ação em t e em t-1, respectivamente. A partir do retorno normal, encontra-se o retorno anormal, que é definido como a diferença entre o retorno observado e o retorno normal esperado. Para cada firma i e informação $X_{t}$ tem-se:

$$
\mathrm{AR}_{\mathrm{i}, \mathrm{t}}=\mathrm{R}_{\mathrm{i}, \mathrm{t}}-\mathrm{E}\left(\mathrm{R}_{\mathrm{i}, \mathrm{t}} \mid X_{t}\right)
$$

Onde $\mathrm{AR}_{\mathrm{i}, \mathrm{t}}, \mathrm{R}_{\mathrm{i}, \mathrm{t}}$ e $\mathrm{E}\left(\mathrm{R}_{\mathrm{i}, \mathrm{t}} \mid X_{t}\right)$ são o retorno anormal, o retorno observado e retorno esperado, respectivamente, para a determinada ação no período t.

Campbell et al. (1997) listam três principais métodos de medição dos retornos anormais: (a) retornos ajustados à média (ou a uma constante); (b) retornos ajustados ao mercado; e (c) modelo de mercado. Neste trabalho, optamos por trabalhar com os retornos ajustados ao mercado por ser um método mais parcimonioso para utilização e por apresentar um desempenho similar ao dos métodos mais sofisticados (Camargos \& Barbosa, 2006).

Além disso, a escolha do método permitiu analisar e testar outras hipóteses usualmente investigadas em estudos sobre F\&As, tais como a hipótese de probabilidade de aquisição e a hipótese de colusão. As duas hipóteses, a primeira proposta por Song e Walkling (2000) e a segunda trabalhadas por Eckbo (1983) e Bernile e Lyandres (2013), têm como objetivo principal analisar a relação entre o retorno anormal das firmas rivais e as possíveis motivações por trás da aquisição na indústria. A utilização dos retornos ajustados ao mercado não apresentaria nenhuma desvantagem se comparada com a utilização de metodologias mais sofisticadas (Brown \& Warner, 1985). Como os ativos analisados 
neste trabalho pertencem à mesma indústria, um possível anúncio de operação de F\&A pode tanto afetar os retornos das firmas participantes quanto os de seus concorrentes. O padrão de comportamento dos retornos esperados ex ante pode ser considerado igual para todos os ativos. Além disso, os retornos esperados ex ante não são necessariamente constantes ao longo do tempo.

\section{Procedimento de estimativa}

O retorno extraordinário ou em excesso é representado pela diferença entre o retorno da ação i na data $t$ e o retorno baseado em um índice de mercado na mesma data, ou seja:

$$
A R_{\mathrm{i}, \mathrm{t}}=R_{\mathrm{i}, \mathrm{t}}-R_{m, t}
$$

Onde $R_{m, t}$ é o retorno da carteira de mercado que, para o trabalho, foi tomado como as variações do Índice Bovespa (Ibovespa). Para verificar o reflexo do evento sobre o valor das empresas, utilizouse o preço de fechamento ajustado de cada empresa selecionada.

Após os cálculos dos retornos extraordinários médios, foi utilizada a técnica do retorno extraordinário médio acumulado ou Cumulative Average Abnormal Return $(\overline{C A R})$ para acomodar múltiplos períodos (Mackinlay, 1997). Assim, os retornos anormais médios acumulados ajustados das ações seguem:

$$
\overline{C A R}_{i,\left(\mathrm{t}_{1}, \mathrm{t}_{2}\right)}=\sum_{t=t_{1}}^{\mathrm{t}_{2}} \overline{A R_{l, t}}
$$

Em que $\overline{C A R}_{i,\left(\mathrm{t}_{1}, \mathrm{t}_{2}\right)}$ é o retorno anormal médio acumulado; $t_{1}$ é o primeiro dia da janela do evento; e $t_{2}$ é o último dia da janela do evento.

\section{Procedimento de teste}

Conforme Campbell et al. (1997), nesta etapa, foram aplicados os testes estatísticos sobre os retornos anormais calculados. O software utilizado para preparação dos dados e cálculo dos retornos anormais foi o $M S$-Excel ${ }^{\circledR}$, e o utilizado para a execução dos testes estatísticos foi o Matlab $^{\circledR}$. Neste estudo, as hipóteses a serem utilizadas para teste de significância estatística foram definidas como:

Hipótese nula $\left(\boldsymbol{H}_{\mathbf{0}}\right)$ - Retornos extraordinários médios acumulados $\overline{C A R}$ iguais a zero.

Hipótese alternativa $\left(\boldsymbol{H}_{1}\right)$ - Retornos extraordinários médios acumulados $\overline{C A R}$ diferente de zero.

Para a verificação de significância estatística das séries de retornos anormais médios de $\overline{\mathrm{AR}} \mathrm{e} \overline{\mathrm{CAR}}$ utilizou-se a estatística $t$.

\section{Discussão dos Resultados}

Nesta seção são apresentados os resultados das análises estatísticas dos oito eventos selecionados, divididos em seis eventos relacionados a F\&As e dois não relacionados. São exibidos os resultados dos oito eventos em ordem cronológica.

Em mercados eficientes, em termos informacionais, a divulgação de um processo de fusão e aquisição deve ser incorporada aos preços dos títulos e às expectativas dos investidores quanto aos resultados futuros do processo de combinação empresarial. Partindo dessa afirmação, esta seção destinase a exibir os retornos das empresas participantes da fusão e das empresas concorrentes. A Tabela 2 apresenta as estatísticas descritivas dos retornos acumulados tanto para os eventos relacionados a F\&As quanto para os não relacionados. Ademais, mostra os resultados para o período completo $(-15$ a +15 dias) e para dois subperíodos $(-5 \mathrm{a}+5$ dias e $-3 \mathrm{a}+3$ dias $)$ para todos os eventos analisados neste trabalho. 
Foram efetuados testes para verificar se a média do retorno acumulado extraordinário é diferente de zero.

Tabela 2

\section{Estatísticas Descritivas dos Retornos dos Oito Eventos}

\begin{tabular}{|c|c|c|c|c|c|}
\hline \multicolumn{6}{|l|}{$1^{o}$ evento $^{\mathrm{a}}$} \\
\hline & Média & Mediana & Desvio padrão & Mínimo & Máximo \\
\hline \multicolumn{6}{|l|}{ SDIA4 } \\
\hline Período $(-15 \mathrm{a}+15)$ & $5,67 \%(9.2349) * * *$ & $5,33 \%$ & 0.034240046 & $0,00 \%$ & $10,94 \%$ \\
\hline Período $(-5 \mathrm{a}+5)$ & $4,95 \%(4.9188)^{* * *}$ & $6,58 \%$ & 0.033360306 & $-0,22 \%$ & $9,10 \%$ \\
\hline Período (-3 a +3) & $3,53 \%(3.5121)^{* * *}$ & $4,38 \%$ & 0.026667812 & $0,00 \%$ & $6,85 \%$ \\
\hline \multicolumn{6}{|l|}{ BRFS3 } \\
\hline Período $(-15 \mathrm{a}+15)$ & $7,61 \%(7.6178)^{* * *}$ & $8,92 \%$ & 0.055652641 & $-0,11 \%$ & $16,33 \%$ \\
\hline Período (-5 a +5) & $6,73 \%(4.0416)^{* * *}$ & $9,72 \%$ & 0.05521811 & $-1,04 \%$ & $13,48 \%$ \\
\hline Período (-3 a +3) & $6,64 \%(3.3863)^{* * *}$ & $9,96 \%$ & 0.051806433 & $0,00 \%$ & $12,30 \%$ \\
\hline \multicolumn{6}{|l|}{$2^{o}$ evento $^{\mathrm{b}}$} \\
\hline & Média & Mediana & Desvio padrão & Mínimo & Máximo \\
\hline \multicolumn{6}{|l|}{ SDIA4 } \\
\hline Período $(-15 \mathrm{a}+15)$ & $0,68 \%(1.3348)$ & $0,55 \%$ & 0.028482337 & $-5,03 \%$ & $5,15 \%$ \\
\hline Período (-5 a +5) & $3,46 \%(7.5444)^{* * * *}$ & $3,76 \%$ & 0.015186109 & $0,00 \%$ & $5,34 \%$ \\
\hline Período (-3 a +3) & $0,55 \%(2.0795)^{*}$ & $0,91 \%$ & 0.007035096 & $-0,67 \%$ & $1,25 \%$ \\
\hline \multicolumn{6}{|l|}{ BRFS3 } \\
\hline Período $(-15 \mathrm{a}+15)$ & $-0,12 \%(-0.2272)$ & $0,00 \%$ & 0.028221772 & $-5,80 \%$ & $4,29 \%$ \\
\hline Período (-5 a +5) & $5,85 \%(8.6725)^{* * *}$ & $6,31 \%$ & 0.022388629 & $0,00 \%$ & $8,95 \%$ \\
\hline Período (-3 a +3) & $-0,51(-1.0237)$ & $-0,25 \%$ & 0.013253846 & $-2,04 \%$ & $1,85 \%$ \\
\hline \multicolumn{6}{|l|}{$3^{o}$ evento $^{\mathrm{c}}$} \\
\hline & Média & Mediana & Desvio padrão & Mínimo & Máximo \\
\hline \multicolumn{6}{|l|}{ SDIA4 } \\
\hline Período $(-15 \mathrm{a}+15)$ & $-13,35 \%(-5.3327)^{* * *}$ & $-4,52 \%$ & 0.139378851 & $-34,15 \%$ & $2,34 \%$ \\
\hline Período (-5 a +5) & $-10,04 \%(-2.7874) * * *$ & $-2,32 \%$ & 0.119467666 & $-26,65 \%$ & $2,36 \%$ \\
\hline Período (-3 a +3) & $-11,40 \%(-2.4043)^{* *}$ & $-3,46 \%$ & 0.125503854 & $-27,50 \%$ & $0,00 \%$ \\
\hline \multicolumn{6}{|l|}{ BRFS3 } \\
\hline Período $(-15 \mathrm{a}+15)$ & $-2,28 \%(-3.7823) * * *$ & $-0,90 \%$ & 0.033611227 & $-9,80 \%$ & $2,57 \%$ \\
\hline Período (-5 a +5) & $-0,56 \%(-1.1663)$ & $0,00 \%$ & 0.015924115 & $-3,37 \%$ & $1,61 \%$ \\
\hline Período (-3 a +3) & $-1,66 \%(-2.855)^{* * *}$ & $-1,08 \%$ & 0.015412855 & $-4,28 \%$ & $0,00 \%$ \\
\hline \multicolumn{6}{|l|}{ MRFG3 } \\
\hline Período $(-15 \mathrm{a}+15)$ & $-0,22 \%(-0.4713)$ & $0,00 \%$ & 0.026031168 & $-7,49 \%$ & $4,19 \%$ \\
\hline Período $(-5 \mathrm{a}+5)$ & $2,43 \%(4.681)^{* * *}$ & $2,66 \%$ & 0.017172111 & $0,00 \%$ & $5,79 \%$ \\
\hline Período (-3 a +3) & $1,34 \%(2.2749)^{*}$ & $1,28 \%$ & 0.015604546 & $-0,24 \%$ & $4,37 \%$ \\
\hline
\end{tabular}


Tabela 2 (continuação)

\begin{tabular}{|c|c|c|c|c|c|}
\hline & Média & Mediana & Desvio padrão & Mínimo & Máximo \\
\hline \multicolumn{6}{|l|}{ BEEF3 } \\
\hline Período $(-15 \mathrm{a}+15)$ & $-30,88 \%(-7.7444) * * *$ & $-21,95 \%$ & 0.221973611 & $-64,61 \%$ & $1,29 \%$ \\
\hline Período $(-5$ a +5$)$ & $-15,78 \%(-4.5562) * * *$ & $-13,75 \%$ & 0.114896238 & $-35,45 \%$ & $0,00 \%$ \\
\hline Período $(-3$ a +3) & $-9,65 \%(-3.1893) * * *$ & $-8,28 \%$ & 0.080012785 & $-20,21 \%$ & $0,00 \%$ \\
\hline \multicolumn{6}{|l|}{$4^{\mathrm{o}}$ evento $^{\mathrm{d}}$} \\
\hline & Média & Mediana & Desvio padrão & Mínimo & Máximo \\
\hline \multicolumn{6}{|l|}{ SDIA4 } \\
\hline Período $(-15$ a +15) & $-5,33 \%(-5.6307) * * *$ & $-5,26 \%$ & 0.052653568 & $-15,52 \%$ & $2,04 \%$ \\
\hline Período $(-5$ a +5) & $3,43 \%(2.4314) * * *$ & $1,60 \%$ & 0.046775285 & $-3,01 \%$ & $11,92 \%$ \\
\hline Período $(-3$ a +3) & $6,49 \%(3.191)^{* * *}$ & $4,75 \%$ & 0.053835283 & $0,00 \%$ & $15,40 \%$ \\
\hline \multicolumn{6}{|l|}{ BRFS3 } \\
\hline Período $(-15 \mathrm{a}+15)$ & $-0,18 \%(-0.5077)$ & $0,27 \%$ & 0.019707901 & $-3,95 \%$ & $3,99 \%$ \\
\hline Período $(-5$ a +5$)$ & $3,76 \%(4.5143) * * *$ & $3,77 \%$ & 0.027586868 & $0,00 \%$ & $8,27 \%$ \\
\hline Período $(-3$ a +3) & $3,41 \%(3.4338) * * *$ & $3,30 \%$ & 0.026278809 & $0,00 \%$ & $7,77 \%$ \\
\hline \multicolumn{6}{|l|}{ MRFG3 } \\
\hline Período $(-15 \mathrm{a}+15)$ & $-1,81 \%(-5.496) * * *$ & $-1,94 \%$ & 0.018323842 & $-4,52 \%$ & $2,27 \%$ \\
\hline Período $(-5$ a +5$)$ & $0,84 \%(1.9842)^{*}$ & $0,15 \%$ & 0.013988572 & $-0,61 \%$ & $3,89 \%$ \\
\hline Período $(-3$ a +3) & $1,03 \%(1.5954)$ & $0,00 \%$ & 0.017079408 & $-0,45 \%$ & $4,06 \%$ \\
\hline \multicolumn{6}{|l|}{ BEEF3 } \\
\hline Período $(-15 \mathrm{a}+15)$ & $-25,73 \%(-10.7376) * * *$ & $-5,82 \%$ & 0.133411252 & $-44,30 \%$ & $0,03 \%$ \\
\hline Período $(-5 \mathrm{a}+5)$ & $-12,85 \%(-5.7246) * * *$ & $-14,05 \%$ & 0.074460214 & $-20,92 \%$ & $0,00 \%$ \\
\hline Período $(-3$ a +3) & $6,07 \%(1.9065)$ & $1,64 \%$ & 0.084200934 & $-0,52 \%$ & $23,28 \%$ \\
\hline \multicolumn{6}{|l|}{$5^{\mathrm{o}}$ evento $^{\mathrm{e}}$} \\
\hline & Média & Mediana & Desvio padrão & Mínimo & Máximo \\
\hline \multicolumn{6}{|l|}{ SDIA4 } \\
\hline Período $(-15 \mathrm{a}+15)$ & $7,81 \%(9.0299) * * *$ & $8,98 \%$ & 0.048188938 & $-2,49 \%$ & $13,77 \%$ \\
\hline Período $(-5$ a +5$)$ & $0,16 \%(-0.1628)$ & $-0,29 \%$ & 0.032231277 & $-5,60 \%$ & $4,09 \%$ \\
\hline Período $(-3 \mathrm{a}+3)$ & $0,09 \%(0.0697)$ & $0,00 \%$ & 0.036318404 & $-4,84 \%$ & $4,93 \%$ \\
\hline \multicolumn{6}{|l|}{ BRFS3 } \\
\hline Período $(-15 \mathrm{a}+15)$ & $4,81 \%(9.8983)^{* * *}$ & $5,39 \%$ & 0.027124788 & $0,00 \%$ & $8,06 \%$ \\
\hline Período $(-5 \mathrm{a}+5)$ & $0,61 \%(1.3035)$ & $0,28 \%$ & 0.015543638 & $-2,43 \%$ & $2,69 \%$ \\
\hline Período $(-3$ a +3) & $0,14 \%(0.2144)$ & $0,00 \%$ & 0.016948651 & $-2,70 \%$ & $2,40 \%$ \\
\hline \multicolumn{6}{|l|}{ MRFG3 } \\
\hline Período $(-15$ a +15) & $8,04 \%(6.6533)^{* * *}$ & $9,05 \%$ & 0.067272838 & $-1,81 \%$ & $18.35 \%$ \\
\hline Período $(-5$ a +5$)$ & $7,30 \%(4.8223)^{* * *}$ & $8,27 \%$ & 0.050215365 & $-0,84 \%$ & $14,33 \%$ \\
\hline Período $(-3$ a +3) & $2,37 \%(2.4031)^{* *}$ & $2,97 \%$ & 0.02607669 & $-0,75 \%$ & $6,19 \%$ \\
\hline
\end{tabular}


Tabela 2 (continuação)

\begin{tabular}{|c|c|c|c|c|c|}
\hline & Média & Mediana & Desvio padrão & Mínimo & Máximo \\
\hline \multicolumn{6}{|l|}{ BEEF3 } \\
\hline Período $(-15$ a +15) & $42,33 \%(11.067) * * *$ & $9,68 \%$ & 0.212956806 & $0,00 \%$ & $75,24 \%$ \\
\hline Período $(-5 \mathrm{a}+5)$ & $10,19 \%(4.0248) * * *$ & $11,90 \%$ & 0.083948423 & $-4,41 \%$ & $18,97 \%$ \\
\hline Período $(-3$ a +3) & $12,43 \%(4.8123) * * *$ & $12,44 \%$ & 0.068356562 & $0,00 \%$ & $19,54 \%$ \\
\hline \multicolumn{6}{|l|}{$6^{o}$ evento $^{\mathrm{f}}$} \\
\hline & Média & Mediana & Desvio padrão & Mínimo & Máximo \\
\hline \multicolumn{6}{|l|}{ BRFS3 } \\
\hline Período $(-15 \mathrm{a}+15)$ & $0,18 \%(1.2353)$ & $0,60 \%$ & 0.008164202 & $-1,33 \%$ & $1,68 \%$ \\
\hline Período $(-5 \mathrm{a}+5)$ & $1,70 \%(5.4263) * * *$ & $1,99 \%$ & 0.01041964 & $0,00 \%$ & $3,04 \%$ \\
\hline Período $(-3$ a +3) & $1,42 \%(4.0472) * * *$ & $1,39 \%$ & 0.009306065 & $0,00 \%$ & $2,44 \%$ \\
\hline \multicolumn{6}{|l|}{ MRFG3 } \\
\hline Período $(-15 \mathrm{a}+15)$ & $-0,34 \%(-2.3204) * * *$ & $-0,18 \%$ & 0.007888315 & $-2,17 \%$ & $0,89 \%$ \\
\hline Período $(-5 \mathrm{a}+5)$ & $0,59 \%(2.9088) * * *$ & $0,82 \%$ & 0.006747857 & $-0,30 \%$ & $1,58 \%$ \\
\hline Período $(-3$ a +3$)$ & $0,86 \%(3.6826)^{* * *}$ & $1,12 \%$ & 0.006172005 & $0,00 \%$ & $1,50 \%$ \\
\hline \multicolumn{6}{|l|}{ BEEF3 } \\
\hline Período $(-15 \mathrm{a}+15)$ & $-2,93 \%(-13.2704) * * *$ & $-2,89 \%$ & 0.012324057 & $-6,17 \%$ & $0,00 \%$ \\
\hline Período $(-5 \mathrm{a}+5)$ & $-0,81 \%(-1.9824)^{*}$ & $-0,28 \%$ & 0.013510157 & $-3,38 \%$ & $0,71 \%$ \\
\hline Período $(-3$ a +3) & $-0,22 \%(-1.0798)$ & $-0,23 \%$ & 0.005413255 & $-1,17 \%$ & $0,64 \%$ \\
\hline \multicolumn{6}{|l|}{$7^{\circ}$ evento $^{g}$} \\
\hline & Média & Mediana & Desvio padrão & Mínimo & Máximo \\
\hline \multicolumn{6}{|l|}{ BRFS3 } \\
\hline Período $(-15 \mathrm{a}+15)$ & $-1,77 \%(-5.1831) * * *$ & $-1,97 \%$ & 0.01905594 & $-5,16 \%$ & $0,73 \%$ \\
\hline Período $(-5$ a +5$)$ & $-2,81 \%(-4.6437) * * *$ & $-3,14 \%$ & 0.020082752 & $-5,46 \%$ & $0,00 \%$ \\
\hline Período $(-3$ a +3$)$ & $-1,79 \%(-2.655)^{* * *}$ & $-2,01 \%$ & 0.017826307 & $-4,35 \%$ & $0,00 \%$ \\
\hline \multicolumn{6}{|l|}{ MRFG3 } \\
\hline Período $(-15 \mathrm{a}+15)$ & $-0,82 \%(-5.2185)^{* * *}$ & $-1,08 \%$ & 0.008789725 & $-2,19 \%$ & $2,32 \%$ \\
\hline Período $(-5 \mathrm{a}+5)$ & $0,39 \%(4.9659) * * *$ & $0,48 \%$ & 0.002599807 & $0,00 \%$ & $0,76 \%$ \\
\hline Período $(-3$ a +3) & $-0,06 \%(-0.5422)$ & $0,00 \%$ & 0.00276995 & $-0,44 \%$ & $0,27 \%$ \\
\hline \multicolumn{6}{|l|}{ BEEF3 } \\
\hline Período $(-15 \mathrm{a}+15)$ & $-5,70 \%(-10.5624) * * *$ & $-5,50 \%$ & 0.030052447 & $-10,71 \%$ & $0,00 \%$ \\
\hline Período $(-5 \mathrm{a}+5)$ & $0,56 \%(2.3541)^{* * *}$ & $0,34 \%$ & 0.007837186 & $-0,82 \%$ & $1,75 \%$ \\
\hline Período $(-3 \mathrm{a}+3)$ & $0,78 \%(2.9335)^{* * *}$ & $0,47 \%$ & 0.00704659 & $0,00 \%$ & $1,88 \%$ \\
\hline \multicolumn{6}{|l|}{$8^{o}$ evento $^{h}$} \\
\hline & Média & Mediana & Desvio padrão & Mínimo & Máximo \\
\hline \multicolumn{6}{|l|}{ BRFS3 } \\
\hline Período $(-15 \mathrm{a}+15)$ & $2,47 \%(6.3613) * * *$ & $3,53 \%$ & 0.021666087 & $-0,51 \%$ & $5,12 \%$ \\
\hline
\end{tabular}


Tabela 2 (continuação)

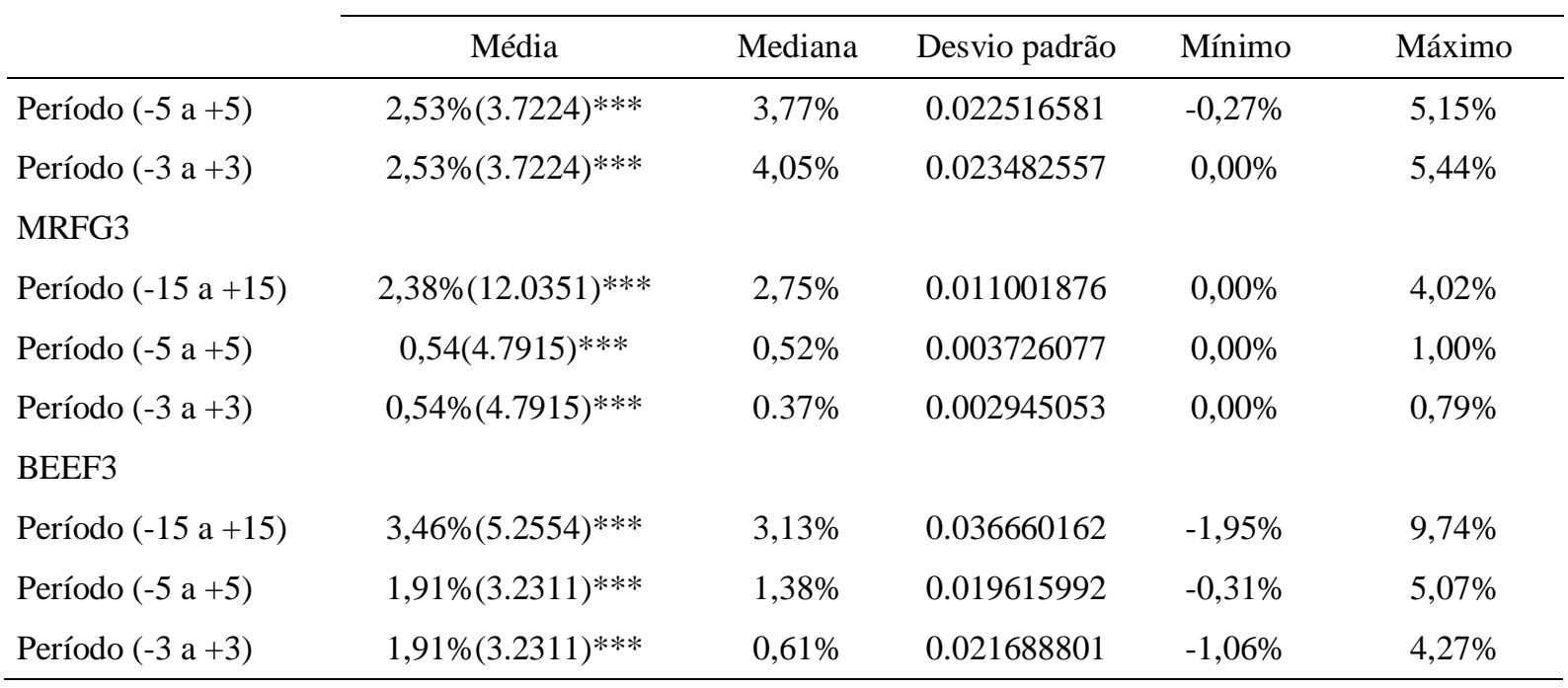

Nota. Fonte: Elaborada pelos autores.

a Primeiro evento - Comportamento de Sadia e Perdigão no período de 26/06/2006 a 07/08/2006. Os retornos das empresas analisadas são os retornos extraordinários acumulados de cada empresa em relação à data do evento; ${ }^{\mathbf{b}}$ Segundo evento Comportamento de Sadia e Perdigão no período de 30/06/2006 a 11/08/2006. Os retornos das empresas analisadas são os retornos extraordinários acumulados de cada empresa em relação à data do evento; ${ }^{\mathbf{c}}$ Terceiro evento - Comportamento de Sadia, Perdigão, Marfrig e Minerva no período de 30/06/2006 a 11/08/2006. Os retornos das empresas analisadas são os retornos extraordinários acumulados de cada empresa em relação à data do evento; d Quarto evento - Comportamento de Sadia, Perdigão, Marfrig e Minerva no período de 17/02/2009 a 02/04/2009. Os retornos das empresas analisadas são os retornos extraordinários acumulados de cada empresa em relação à data do evento; ${ }^{\mathbf{e}}$ Quinto evento - Comportamento de Sadia, Perdigão, Marfrig e Minerva no período de 27/04/2009 a 09/06/2009. Os retornos das empresas analisadas são os retornos extraordinários acumulados de cada empresa em relação à data do evento; f Sexto evento - Comportamento de BRF, Marfrig e Minerva no período de 27/01/2011 a 14/03/2011. Os retornos das empresas analisadas são os retornos extraordinários acumulados de cada empresa em relação à data do evento; ${ }^{\mathbf{g}}$ Sétimo evento - Comportamento de BRF, Marfrig e Minerva no período de 18/05/2011 a 30/06/2011. Os retornos das empresas analisadas são os retornos extraordinários acumulados de cada empresa em relação à data do evento; ${ }^{\mathbf{h}}$ Oitavo evento - Comportamento de BRF, Marfrig e Minerva no período de 21/06/2011 a 03/08/2011. Os retornos das empresas analisadas são os retornos extraordinários acumulados de cada empresa em relação à data do evento.

Os símbolos $* * *, * * \mathrm{e} *$ representam o retorno extraordinário estatisticamente significante a $1 \%, 5 \%$ e $10 \%$, respectivamente. Os valores da estatística $t$ estão entre parênteses.

A Tabela 2 exibe os retornos extraordinários acumulados da Sadia e da Perdigão no período completo e nos dois subperíodos para o primeiro evento. Para este, só foram calculados os resultados para as empresas participantes do processo de aquisição, pois a Minerva e a Marfrig ainda não estavam listadas na BM\&FBovespa.

Para o período de 31 dias, os retornos extraordinários acumulados obtidos pela metodologia do retorno ajustado ao mercado, incluindo-se a data do anúncio, foram 5,67\% para a Sadia e 7,61\% para a Perdigão. Esse resultado está em linha com os achados de Agarwal e Singh (2006) e com os resultados no Brasil de Pinheiro e Carvalhal (2011), que apresentaram, em seus estudos, que tanto os acionistas das firmas adquirentes quanto os das adquiridas obtêm retornos extraordinários positivos em anúncios de F\&As. Além disso, os resultados foram significantes estatisticamente.

Nesse evento, no qual a Sadia aproveitou-se do controle difuso implementado na época pela Perdigão para tentar uma oferta hostil, a Perdigão apresentou para o período de 31 dias os melhores retornos positivos em comparação a todos os outros eventos estudados neste trabalho.

Ainda, esse primeiro evento analisado foi estudado também por Callas (2009), que obteve resultados diferentes ao analisar os retornos acumulados nas empresas participantes. Em seu estudo, o autor trabalhou com o retorno ajustado a média em uma janela de 11 dias $(-5$ a +5 dias). Callas (2009) também não utilizou cotações de fechamento diárias, reais, ajustada por provento, inclusive dividendos, nem usou a forma logarítmica para os retornos. Em seus resultados, o autor reportou que os retornos 
extraordinários acumulados foram positivos e estatisticamente não significantes tanto para a Perdigão quanto para Sadia. Os retornos calculados foram, respectivamente, $26 \%$ e $13 \%$.

Na Tabela 2, elencam-se os retornos extraordinários acumulados da Sadia e da Perdigão para o segundo evento (revogação definitiva da Sadia para a compra da Perdigão). Os retornos das empresas concorrentes não foram calculados, pois a Minerva e a Marfrig ainda não tinham sido listadas na BM\&FBovespa.

Os retornos no período completo não foram significantes como no primeiro subperíodo $(-5$ a +5 dias), em que todos exibiram médias significantes (nível de 1\%). Dessa forma, para o período de 31 dias, não se rejeitou a hipótese nula. No subperíodo de 11 dias $(-5$ a +5$)$, a Sadia e a Perdigão apresentaram retornos positivos e significantes de $3,46 \%$ e $5,85 \%$, respectivamente. Com isso, as duas empresas obtiveram aumento dos preços em suas ações negociadas na BM\&FBovespa.

No terceiro evento (situação financeira delicada da Sadia), observou-se que os retornos de todas as empresas selecionadas no estudo apresentaram desempenhos negativos e significantes (nível de 1\%) na maioria dos períodos. Isso pode indicar que a crise financeira não era somente da Sadia, mas sim do setor como um todo.

O período completo de 31 dias $(-15 \mathrm{a}+15)$ relacionado à situação financeira da Sadia exibiu a maior queda nos preços das ações das empresas analisadas. Marfrig e a Sadia apresentaram os piores retornos negativos do período, $-30,88 \%$ e $-13,35 \%$ respectivamente. Esse evento também foi analisado por Barreto (2011), que, em seu trabalho, descreveu que a notícia da crise financeira da Sadia pegou o mercado de surpresa, fato que refletiu no mercado acionário e levou o valor de mercado da empresa a cair quase $50 \%$ após o anúncio.

O anúncio de que a Sadia estava, de fato, buscando oportunidades para a fusão com a Perdigão (acordo operacional Sadia-Perdigão) foi estudado no evento quatro (ver Tabela 2). As empresas participantes do acordo tiveram resultados negativos para o período de 31 dias. Esse resultado contraria a literatura corrente, pois as pesquisas que abordam o tema reportam que as firmas adquiridas obtêm retornos positivos a partir do anúncio do processo. Uma possível justificativa para este resultado seria a crise financeira enfrentada pela Sadia no período, causada principalmente por operações de hedge malsucedidas. Os resultados mostraram, também, que a Sadia e a Perdigão obtiveram os maiores retornos positivos e significantes para os subperíodos $(-5 a+5$ dias e $-3 a+3$ dias $)$.

As empresas concorrentes Minerva (BEEF3) e Marfrig (MRFG3) revelaram retornos negativos e significantes para o período (-15 a +15 dias), $-25,73 \%$ e $-1,81 \%$, respectivamente. Esses retornos confrontam os trabalhos de Eckbo (1983) e Fee e Thomas (2004), que afirmaram que, em anúncios de F\&As, as empresas rivais apresentam retornos positivos. Um dos motivos para este resultado poderia ser uma crise enfrentada pelo setor, pois, nesse período, todas as empresas analisadas obtiveram retornos negativos. Os resultados, porém, foram diferentes ao analisar o período de -3 a +3 dias, pois ocorreu um aumento de preço para ambas as empresas nesse intervalo de sete dias. Entretanto, nesse período, os resultados não foram significantes estatisticamente.

O quinto evento analisado tratou dos possíveis efeitos em mercado decorrentes do anúncio da fusão entre Sadia e Perdigão. Vale ressaltar que, como a Perdigão, ao final, deteve $68 \%$ da BRF, para a análise do processo de fusão, a Perdigão torna-se a empresa adquirente e a Sadia, a adquirida.

Esse episódio foi o mais relevante estatística e economicamente deste trabalho. Os resultados indicaram que, ao considerar o período completo, os retornos extraordinários para todas as empresas estudadas foram positivos e significantes, sendo que os da adquirida (média de $7,81 \%$ ) foram maiores do que os da adquirente (média de 4,81\%). Esse resultado está em linha com a literatura nacional (e.g. Pinheiro \& Carvalhal, 2011) ao constatar que os retornos das duas empresas são positivos e diferentes de zero (ver Tabela 2).

Os resultados variaram de acordo com a janela de evento estipulada. Para o subperíodo de 11 dias $(-5$ a +5$)$, o retorno extraordinário da empresa-alvo foi positivo, porém bem inferior ao do período 
completo $(-15$ a +15$)$, enquanto o retorno extraordinário da empresa adquirente $(0.61 \%)$ foi maior do que aquele da empresa-alvo (0.16\%). Mas, como os resultados para os subperíodos não são significantes, não é possível considerá-los para a análise.

Outra verificação que este estudo detectou foi que a fusão resultou em preços maiores para as empresas rivais em todos os períodos analisados, apresentando retornos extraordinários positivos e significantes. A Minerva apresentou o maior retorno no período completo (42,33\%), e a Marfrig, 8,04\%. Isso confirma os achados de Fee e Thomas (2004), Shahrur (2005) e Bernile e Lyandres (2013), que verificaram que as empresas concorrentes apresentam retornos positivos após anúncios de operações de F\&A. O resultado também está em linha com os resultados de Song e Walkling (2000, p. 144), que elaboraram a "hipótese de probabilidade de aquisição" para explicar as razões para esses retornos positivos. Essa hipótese consiste na expectativa de que as empresas rivais obtenham retornos positivos, por conta delas, posteriormente, tornarem-se alvos em novos processos de F\&As com as empresas participantes. Especificamente, a Minerva Foods e a BRF assumiram posteriormente um acordo de investimentos, em que a primeira assumiu a divisão de bovinos da BRF, em operação que incluiu a transferência de $15,2 \%$ das ações da Minerva para a BRF.

O sexto evento da pesquisa mostrou os retornos decorrentes do julgamento do processo envolvendo conselheiros e diretores da Sadia (em que a Justiça brasileira condenou, pela primeira vez, por informação privilegiada). Nesse período, as ações da Sadia já haviam sido incorporadas às da Perdigão, cujo nome foi mudado para BRF. Os dados encontrados no período de 31 dias indicaram retornos extraordinários e negativos, com médias significantes para as empresas concorrentes - Marfrig e Minerva. A BRF exibiu retorno próximo a zero e não significante.

Nos períodos de 11 dias $(-5 \mathrm{a}+5)$ e de 7 dias $(-3 \mathrm{a}+3)$, as empresas que apresentaram retornos significantes tiveram resultados positivos próximos a zero. Os resultados encontrados para esse evento podem ser interpretados como ocorrências não relevantes economicamente para o mercado.

O primeiro julgamento do CADE sobre a fusão Sadia-Perdigão, em que o primeiro relator votou contra a fusão das empresas, foi retratado no sétimo evento. Os resultados evidenciados pelo estudo de evento para o período completo de 31 dias revelaram que as empresas obtiveram retornos negativos e significantes a $1 \%$ (ver Tabela 2). Entretanto, no período de 11 dias, os resultados foram diferentes, pois apresentaram retorno negativo somente para a BRF.

No dia 13 de julho de 2011, a BRF e o CADE selaram acordo e a fusão entre Sadia e Perdigão foi aprovada. Porém, antes da efetivação do acordo, as ações da Sadia já tinham sido incorporadas às da Perdigão, cujo nome mudou para BRF. Dessa forma, os resultados do oitavo evento apresentaram os retornos apenas para três empresas: BRF, Marfrig e Minerva.

Para o período de 31 dias, os retornos extraordinários acumulados foram de 2,47\% para a BRF, 2,38\% para a Marfrig e 3,46\% para a Minerva. O resultado mostrou um aumento de valor nas ações de todas as empresas analisadas no trabalho. Com o resultado desse evento, pode-se rejeitar a hipótese de colusão, pois as rivais apresentaram retornos positivos e estatisticamente significantes. Isso também confirma os achados dos trabalhos de Eckbo (1983) e Bernile e Lyandres (2013). Uma possível justificativa para o aumento dos preços das ações das firmas analisadas (participantes e rivais) seria a eficiência do processo de fusão, ao constatar que a fusão ajudou as empresas e o setor a crescerem com a nova configuração do mercado.

\section{Conclusões}

O presente trabalho buscou avaliar o processo de F\&A como estratégia de crescimento e identificar a criação de valor ou não tanto para as empresas participantes quanto para suas principais concorrentes. Com o intuito de adicionar à literatura internacional em single country e case study e à literatura nacional, foram analisadas e testadas hipóteses regularmente investigadas no tema F\&As, tais 
como a de probabilidade de aquisição e a de colusão. A contribuição à área neste trabalho foi adicionar evidências empíricas no caso brasileiro de operações de F\&A.

Nos eventos relacionados à fusão e aquisição, foram encontrados os dados mais relevantes estatística e economicamente. O primeiro evento, oferta hostil da Sadia para a compra da Perdigão, apresentou retornos positivos e significantes para todos os períodos analisados. O segundo evento, revogação definitiva da Sadia para a compra da Perdigão, exibiu implicações diferentes. Somente no período de 11 dias $(-5 \mathrm{a}+5)$ as empresas estudadas exibiram retornos significativos e positivos, o que pode evidenciar que os anúncios envolvendo fusões e aquisições abrangem mais expectativas no mercado do que as revogações de uma F\&A.

O quarto evento, anúncio de que a Sadia estava, de fato, buscando oportunidades para fusão com a Perdigão, exibiu retornos negativos para todas as empresas analisadas. Ademais, apresentou um resultado negativo para a empresa adquirida (Sadia), o que contraria a literatura, pois os trabalhos sobre F\&As verificaram que as firmas adquiridas obtêm retornos positivos a partir do anúncio do processo.

O quinto evento deste trabalho foi o mais importante estatística e economicamente. Nele, as análises indicaram que os retornos extraordinários de ambas as empresas foram positivos e estatisticamente significantes para o período de $-15 \mathrm{a}+15$ dias da data do anúncio da fusão. Os resultados para o período completo apresentaram as mesmas conclusões de Agarwal e Singh (2006), ao constatar que os retornos das duas empresas são positivos e diferentes de zero.

Outra constatação a que este estudo chegou foi que a fusão resultou em preços maiores para as empresas rivais, apresentando retornos extraordinários positivos. Isso está em linha com os achados de Fee e Thomas (2004), que indicaram retornos positivos para as rivais. Além disso, esta pesquisa comprovou a hipótese de probabilidade de aquisição elaborada por Song e Walking (2000), ao constatar retornos positivos para rivais no momento do anúncio da fusão Sadia-Perdigão. Já a análise do oitavo evento, em que BRF e CADE selaram o acordo e a fusão entre Sadia e Perdigão foi aprovada, não condiz com a hipótese de colusão discutida por Eckbo (1983) e Bernile e Lyandres (2013).

Este trabalho revelou evidências de retornos extraordinários positivos e estatisticamente significativos tanto para empresa adquirente quanto para a empresa adquirida, sendo que os retornos da empresa adquirida foram maiores do que aqueles da adquirente. $\mathrm{O}$ resultado contraria a regularidade de retornos próximos a zero para empresas adquirentes. Outra verificação que este estudo detectou foi que a fusão resultou em preços maiores em mercado acionário para as empresas rivais em todos os períodos analisados, apresentando retornos extraordinários positivos e significantes.

Os resultados obtidos confirmam algumas suposições teóricas e refutam outras. No Brasil, há espaço para maior detalhamento a partir de análise de outras operações de F\&A, em que se atente para especificações setoriais. Assim, poder-se-ia analisar a reação de todo o segmento de mercado em que essas empresas estão situadas. Outros estudos subsequentes (usuais na literatura) poderiam abordar a influência de alguns fatores como tamanho, intangibilidade e desempenho sobre a criação de valor tanto para as empresas adquirentes quanto para as adquiridas nos eventos de F\&As.

Esta pesquisa exibiu uma limitação em sua parte empírica, que deve ser levada em consideração em pesquisas futuras. Essa limitação diz respeito à quantidade de empresas analisadas. Como o objetivo do estudo foi analisar somente os retornos tanto das firmas participantes do processo de fusão da BRF quanto das suas concorrentes listadas na BM\&FBovespa, a amostra analisada se restringiu a poucas firmas. Dessa forma, os resultados não podem ser generalizados para o total de F\&As ocorridas no Brasil. 


\section{Referências}

Agarwal, M., \& Singh, H. (2006). Merger announcements and insider trading activity in India: an empirical investigation. Investment Management and Financial Innovations, 3(3), 140-154.

Almeida, H., Campello, M., \& Hackbarth, D. (2011). Liquidity mergers. Journal of Financial Economics, 102(3), 526-558. doi: 10.3386/w16724

Amato, F. (2011, julho 13). BRF e Cade selam acordo e fusão entre Sadia e Perdigão é aprovada. G1 Globo.com. Recuperado de http://g1.globo.com/economia/negocios/noticia/2011/07/brf-e-cadeselam-acordo-e-fusao-sadia-e-perdigao-e-aprovada.html

Andrade, G., Mitchell, M., \& Stafford, E. (2001). New evidence and perspectives on mergers. Journal of Economic Perspectives, 15(2), 103-120. doi: 10.1257/jep.15.2.103

Associação Brasileira das Entidades dos Mercados Financeiro e de Capitais. (2013). Boletim Anbima. Recuperado de http://portal.anbima.com.br/informacoes-tecnicas/boletins/fusoes-eaquisicoes/Documents/Boletim_fusoes_e_aquisicoes_2013-1S.pdf

Ato de concentração $n^{\circ}$ 08012.004423/2009-18, de 07 de julho de 2011. (2011). Dispõe sobre a fusão Sadia e Perdigão. Diário Oficial da União. Brasília, DF: Conselho de Administrativo de Defesa Econômica.

Barreto, R. G. (2011). Operações de hedge cambial em empresas não financeiras: um estudo de caso das empresas Aracruz Celulose e Sadia (Dissertação de mestrado). Universidade Federal do Rio de Janeiro UFRJ, Rio de Janeiro, RJ, Brasil.

Bena, J., \& Li, K. (2014). Corporate innovations and mergers and acquisitions. The Journal of Finance, 69(5), 1923-1960. doi: 10.1111/jofi.12059

Bernile, G., \& Lyandres, E. (2013). The effects of horizontal merger synergies on competitors, customers, and suppliers [Working Papers Series]. Retrieved from http://papers.ssrn.com/sol3/papers.cfm?abstract_id=2311560

Bhagat, S., Dong, M., Hirsheifer, D., \& Noah, R. (2005). Do tender offers create value? New methods and evidence. Journal of Financial Economics, 76, 3-60. doi: 10.1016/j.jfineco.2004.05.002

Bradley, M., Desai, A., \& Kim, E. H. (1988). Synergistic gains from corporate acquisitions and their division between the stockholders of target and acquiring firms. Journal of Financial Economics, 21(1), 3-40. doi: 10.1016/0304-405X(88)90030-X

Brito, G. A., Batistella, F. D., \& Famá, R. (2005). Fusões e aquisições no setor bancário: avaliação empírica do efeito sobre o valor das ações. Revista de Administração da USP, 40(4), 353-360.

Brown, S. J., \& Warner, J. B. (1985). Using daily stock returns: the case of event study. Journal of Financial Economics, 14(1), 3-31. doi: 10.1016/0304-405X(85)90042-X

Callas, C. (2009). Entrincheiramento ou alinhamento de interesses? Analise da oferta hostil da Sadia pelo controle da Perdigão à luz da teoria de agência (Dissertação de mestrado). Fundação Getúlio Vargas, Escola de Pós-Graduação em Economia, Rio de Janeiro, RJ, Brasil.

Camargos, M. A., \& Barbosa, F. V. (2006). Eficiência informacional do mercado de capitais brasileiro pós-Plano Real: um estudo de eventos dos anúncios de fusões e aquisições. Revista de Administração da USP, 41(1), 43-58. 
Camargos, M. A., \& Coutinho, E. S. (2008). A teoria da firma e a fundamentação teórica para fusões e aquisições: uma análise de suas interfaces. Revista RAC-Eletrônica, 2(2), 273-295. Recuperado de http://www.anpad.org.br/periodicos/arq_pdf/a_738.pdf

Campbell, J., Lo, A., \& Mackinlay, A. C. (1997). The econometrics of financial markets. New Jersey: Princeton University Press.

Datta, D., Pinches, G., \& Narayanan, V. K. (1992). Factors influencing wealth creation from mergers and acquisitions: a meta-analysis. Strategic Management Journal, 13(1), 67-84. doi: $10.1002 /$ smj.4250130106

Eckbo, E. B. (1983). Horizontal mergers, collusion, and stockholder wealth. Journal of Financial Economics, 11(1/4), 241-273. doi: 10.1016/0304-405x(83)90013-2

Exame.com. (2011, janeiro 27). Sadia perde cerca de R\$ 2,5 bi com câmbio em 2008, diz Brascan. Revista Exame, Negócios. Recuperado de http://exame.abril.com.br/negocios/noticias/sadiaperde-cerca-r-2-5-bi-cambio-2008-diz-brascan-417570/

Fee, E., \& Thomas, S. (2004). Sources of gains in horizontal mergers: evidence from customer, supplier, and rival firms. Journal of Financial Economics, 74(3), 423-460. doi: 10.1016/j.jfineco.2003.10.002

Gorton, G., Kahl, M., \& Rosen, R. J. (2009). Eat or be eaten: a theory of mergers and firm size. The Journal of Finance, 64(3), 1291-1344. doi: 10.1111/d.1540-6261.2009.01465.x

Habibe, M. C. (2006). Aquisição de empresas na bolsa de valores: uma análise das empresas brasileiras (Dissertação de mestrado). Escola de Pós-Graduação em Economia, Fundação Getúlio Vargas, Rio de Janeiro, RJ, Brasil.

Hackbart, D., \& Morellec, E. (2008). Stock returns in mergers and acquisitions. The Journal of Finance, 63(3), 1213-1252. doi: 10.1111/j1540-6261.2008.01356.x

Hosken, D., \& Simpson, J. D. (1998). Are retailing mergers anticompetitive? An event study analysis [Working Paper $\mathrm{n}^{\mathrm{o}}$ 216]. Federal Trade Commission. Retrieved from http://www.ftc.gov/sites/default/files/documents/reports/are-retailing-mergers-anticompetitiveevent-study-analysis/wp216.pdf

Kuipers, D. R., Miller, D. P., \& Patel, A. (2009). The legal environment and corporate valuation: evidence from cross-border takeovers. International Review of Economics \& Finance, 18(4), 552567. doi: 10.1016/j.iref.2008.09.013

Leal, R., Almeida, V., \& Bortolon, P. (2013). A produção científica brasileira em finanças no período 2000-2010. Revista de Administração de Empresas, 53(1), 46-55. doi: 10.1590/S003475902013000100005

Li, J. T. S., \& Lucinda, C. R. (2009, julho). Uma análise do potencial anticompetitivo da fusão Oi-BrT usando informações do mercado de capitais. Encontro Brasileiro de Finanças, São Leopoldo, RS, Brasil, 9.

Mackinlay, A. C. (1997). Event studies in economics and finance. Journal of Economics Literature, 35(1), 13-39. doi: 10.2307/2729691

Madureira, D. N. (2006, dezembro). Preparada para crescer- com estrutura de capital mais flexível, companhia busca expansão em três novos nichos. Revista Capital Aberto, Governança Corporativa, pp. 41-42. 
Málaga, F. K. (2007). Estudo do risco sistêmico das empresas resultantes de fusão e aquisições e as expectativas dos investidores e dos gestores (Tese de doutorado). Faculdade de Economia, Administração e Contabilidade, Universidade de São Paulo, São Paulo, SP, Brasil.

Manne, H. G. (1965). Mergers and the market for corporate control. The Journal of Political Economy, 73(2), 110-120. doi: 10.1086/259036

Moeller, S., Schlingemann, F., \& Stulz, R. (2004). Firm size and the gains from acquisitions. Journal of Financial Economics, 73(2), 201-228. doi: 10.1016/j.jfineco.2003.07.002

Novo, A. (2009, maio 19). Perdigão terá 68\% da Brasil Foods e Sadia, 32\%. O Globo, Economia. Recuperado de http://oglobo.globo.com/economia/perdigao-tera-68-da-brasil-foods-sadia-323153066

Parecer do Comitê de Termo de Compromisso, de 13 de fevereiro de 2008. (2008). ref.: processo administrativo sancionador CVM no SP 2007/0119. Brasília, DF: CVM.

Phalippou, L., Xu, F., \& Zhao, H. (2013, January). Acquiring acquirers. Proceedings of the AFA 2013 San Diego Meetings Paper. San Diego, USA.

Pinheiro, A., \& Carvalhal, A. (2011). Abnormal returns in mergers and acquisitions: new evidence in Brazil. Inventi Impact: Emerging Economies, 2011(1), 10-14.

Ponde, J. L., Fagundes, J., \& Possas, M. (1997). Custos de transação e políticas de defesa da concorrência. Revista de Economia Contemporânea, 1(2), 115-135.

Sadia S. A. (2009). Comunicado ao mercado. Recuperado de http://siteempresas.bovespa.com.br/consbov/VisualizaArquivo.asp?protocolo=193930\&funcao= download $\&$ Site $=\mathrm{C}$

Shahrur, H. (2005). Industry structure and horizontal takeovers: analysis of wealth effects on rivals, suppliers, and corporate customers. Journal of Financial Economics, 76(1), 61-98. doi: 10.1016/j.jfineco.2004.01.001

Song, M. H., \& Walkling, R. A. (2000). Abnormal returns to rivals of acquisition targets: a test of the acquisition probability hypothesis'. Journal of Financial Economics, 55(2), 143-171. doi: 10.1016/S0304-405X(99)00048-3

Steinberg, F., \& Silva, A. L. C. (2009). Governança corporativa e ganhos de fusões e aquisições no Brasil. In A. P. Figueiredo \& L. F. Motta (Eds.), Decisões de investimentos (Vol. 7, pp. 169-190). Rio de Janeiro: Mauad X.

Viegas, C. A. (2006). Fusões e aquisições na indústria de alimentos e bebidas do Brasil: análise dos efeitos nos preços ao consumidor (Tese de doutorado). Faculdade de Economia, Administração e Contabilidade, Universidade de São Paulo, São Paulo, SP, Brasil.

Zafalon, M. (2009, março 17). Sadia e Perdigão deve unificar operação. Folha de São Paulo, Mercado. Recuperado de http://www1.folha.uol.com.br/fsp/dinheiro/fi1703200902.htm\#_=_

\title{
Dados dos Autores
}

\author{
Patrícia Ribeiro Romano \\ Caixa Postal 1524, Campus Universitário Lagoa Nova, 59078-970, Natal, RN, Brasil. E-mail: \\ patricia_ribeiro_romano@hotmail.com \\ Vinicio de Souza e Almeida \\ Caixa Postal 1524, Campus Universitário Lagoa Nova, 59078-970, Natal, RN, Brasil. E-mail: almeida.vinicio@ gmail.com \\ RAC, Rio de Janeiro, v. 19, n. 5, art. 4, pp. 606-625, Set./Out. 2015 \\ www.anpad.org.br/rac $($ (c)
}

